\title{
Unilever purchases British plant breeding interests
}

\section{London}

IN a move aimed at extending its growing agricultural interests, Unilever, the Anglo-Dutch consumer conglomerate, is to pay the British government $£ 66$ million for the plant breeding assets of the Plant Breeding Institute (PBI) and the National Seed Development Organization (NSDO), which markets new varieties produced by PBI. The deal will be completed by 30 September this year.

The PBI/NSDO package attracted widespread interest from the food, chemical and agricultural industries; after

\section{AIDS programme head}

\section{London}

$D_{R}$ Geoffrey Schild, director of the National Institute for Biological Standards and Control (NIBSC), has been appointed director of the Medical Research Council's (MRC) directed programme of AIDS (acquired immune deficiency syndrome) research from October.

Schild, 51, will divide his time between directorial duties at NIBSC, which has

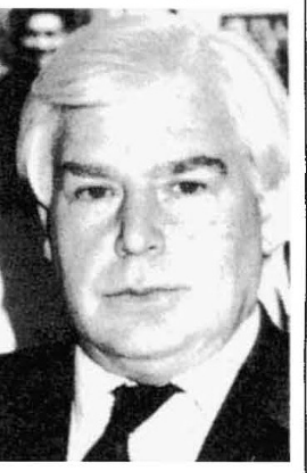
recently been designated a World Health Organisation collaborating centre on AIDS, and the MRC programme. He succeeds Sir James Gowans as head of the directed research programme, begun early this year.

MRC has $\mathfrak{£ 1 4 . 5}$ million to allocate for research into vaccines and antiviral therapy, with some projects already under way.

K.J.

\section{Soviet superconductors \\ London}

THE Soviet Union is to produce a standard high-temperature superconducting ceramic in sufficient quantities to supply all Soviet laboratories working on superconductivity. Following the production of the first Soviet high-temperature superconductor earlier this year in Sverdlovsk, all interested laboratories began producing their own materials. As the superconducting properties of different ceramics differ considerably, the production of a standard material will allow experiments carried out in different parts of the country to be compared and correlated. Bulk production of the material is to begin at once.

V.R. the sale was announced in May (see Nature 327, 176; 1987), the government received "dozens" of applications for the confidential memorandum of information, reserved for "serious" bidders. Unilever was shortlisted with Imperial Chemical Industries (ICI) and the food group Booker. Of the three, Unilever's bid was the highest by a considerable, though unspecified, margin.

The plant science activities of PBI were not included in the package, but will be retained by the Agricultural and Food Research Council (AFRC) and relocated in 1990 to the new Institute of Plant Science Research. The decision to hive off the scientists provoked hostility from within PBI, which complained that the close interaction between the molecular biologist and the breeder was fundamental to the institute's success. More than 80 per cent of NSDO's revenue is derived from royalties on varieties produced by $\mathrm{PBI}$; in 1986, PBI/NSDO generated in come of $£ 11.3$ million with an operating profit of $£ 4.5$ million. In the same period, PBI received $£ 3$ million in government grants, with a further $£ 1$ million in contracts. The proceeds from the sale will go to the Treasury.

Given that the sale had been decided, staff at PBI felt that the terms being offered by Unilever were more favourable than those of the other two shortlisted bidders. Unilever intends to allow PBI (to be renamed PBI Plant Breeding) to retain a degree of autonomy and will move its own pea- and bean-breeding programmes to PBI's Cambridge site. PBI's breeding programmes, for wheat, barley, potatoes and field beans, will be retained.

Most of Unilever's plant science research is carried out at Colworth in Bedfordshire, where it is best known for its work on cloning oil palms. Its current agricultural activities focus largely on plantation crops. The Colworth laboratory is also carrying out research on the genetic manipulation of oilseed rape. Although PBI has a rapidly expanding oilseed rape breeding programme, this was not included in the sale. Instead it will go to the Agricultural Genetics Company (AGC) in settlement of various claims that AGC has on PBI. AGC, set up in 1983 , was given first option to exploit biotechnological discoveries made by AFRC.

Last year, Unilever's agricultural activities accounted for $£ 632$ million of the group's total turnover of $£ 17,140$ million. It produced an operating profit of $£ 35$ million, of a total $£ 1,124$ million. Unilever's overall research and development budget was $£ 305$ million last year, compared with $£ 253 \mathrm{~m}$ for 1985 .

\section{SDI plans play safe with Congress}

\section{Washington}

THE US Strategic Defense Initiative Organization (SDIO) appears to have gone out of its way to avoid confrontation with congressional critics in its new plans for a series of tests of anti-missile interceptor rockets and tracking satellites. All tests have been designed to comply with a strict interpretation of the Anti-Ballistic Missile (ABM) Treaty.

The new plans were revealed last week in a series of environmental impact assessments that the Department of Defense is required to make before undertaking major operations. Thirteen large-scale tests are planned for the next five years and paint a picture of a missile defence system that is based largely on conventional technology. Plans to test exotic laser and particle-beam weapons are left for the future, while emphasis is placed on building on successes already scored in intercepting incoming missiles with high-acceleration rockets.

For the first time, all the major components of the system are to be tested, including satellite surveillance and command, ground-based surveillance and tracking, battle management, control and communications, and two types of 'kinetic-kill' interceptor rocket. One, the exoatmospheric reentry vehicle (ERIS) will be carried aloft on a large missile and will try to hit incoming warheads before they can re-enter the atmosphere. The other, the space-based interceptor (SBI) is intended to destroy missiles much earlier. In its final configuration, SBI homing rockets would be fired from an orbiting space platform and collide with missiles as they leave the atmosphere at the end of their boost phase. But in the planned tests, the ABM Treaty ban on testing "space-based" systems will be observed and the homing rockets fired from the sub-orbital flights of a large booster rocket.

The tests will be extremely expensive to perform. From four to seven Minuteman or Polaris rockets will be launched from California to provide targets for ERIS missiles fired from the Kwajalein Atoll in the Pacific Ocean. Smaller sounding rockets will be used to test the SBI homing rockets intercept capability at the Kwajalein Atoll. A new satellite will be also be needed to test space-based surveillance and tracking systems. Opposition to the plan may still come in the SDI review under way at the Department of Defense and from Congress. Earlier attempts in the Senate to restrict SDI testing (see Nature 327,$175 ; 1987)$ ground to a halt as the Irangate hearings got under way but are expected to be revived again in September.

Alun Anderson 